\title{
Why is research still invisible in further education?
}

\author{
Carla Solvason \\ University of Worcester, UK \\ Geoffrey Elliott \\ University of Worcester, UK
}

\begin{abstract}
This article takes as its starting point earlier research reported by Geoffrey Elliott in 1996. That study found that research was consistently marginalised in the FE sector, and identified a number of structural factors that contributed to this 'invisibility'. This new study draws upon a small sample of lecturers who belong to a Further and Higher Education Early Years Partnership. Through the participants' voices and perspectives, the authors identify continuing dissonance and issues of research marginalisation. The discussion also highlights contemporary educational discourse, with its predominant focus upon measurable value at the expense of values, as a key factor in sustaining a culture that is antithetic to thoughtful reflection and research. The authors identify the development of a 'collaborative centralised' research community as critical to an alternative possibility for research in further education.
\end{abstract}

Keywords: research; further education; lecturer; tutor; culture.

Education should begin in research and end in research...An education which does not begin by evoking initiative and end by encouraging it must be wrong. For its whole aim is the production of active wisdom. (Whitehead, 1962, pp.57-8)

Seventeen years ago Elliott (1996) opened his article which investigated the scarcity of research in Further Education (FE) citing these words, which are, despite the passage of some considerable time, no less relevant today. In 1996, Elliott explored literature that discussed the marginalisation of research in the FE sector. Today we would like to re-open 
this debate, but adding one important feature that was missing previously: the voice of the FE lecturer (hereafter 'tutor'). This article represents the voices of the two authors and five colleagues. The first author is a university lecturer without direct experience of working within colleges, though having worked closely with them, whilst the second has worked in both sectors. Of the contributors, three of these are currently teaching within the FE environment, one has moved from FE to higher education (HE) and one is an Early Years practitioner who has moved into HE. Therefore this piece represents a variety of perspectives, but predominantly that of the FE tutor. Our intention and method, following Carr and Kemmis (1986, p.198), has been to involve these colleagues 'directly in theorizing their own practice and revising their theories self-critically in the light of their practical consequences'.

Over the past two years the first author has been part of a university Early Years Partnership Management Team that works very closely and very successfully with eight partner colleges and their staff, all members of course teams teaching a university Foundation Degree in Early Years. The most notable disparity in this relationship is the high volume of teaching and assessment that FE tutors have to deal with. The "heavy teaching loads, shortage of money and...complex character of the further education sector' (Cantor and Roberts, 1972/1986, p.256) that Elliott cited remain unchanged. Elliott's article extensively explored funding issues related to this, but funding is not something that was recognised as being of importance to the college partners, or only indirectly insomuch as time costs money, and investment in research is not considered a relevant use of time. Their perspectives have led us to focus instead upon the cultures (practices, traditions and beliefs) and resulting ethos of the FE colleges that they work within. In the context of the current government drive to place increased higher education student numbers into FE colleges (HEFCE, 2012), it is crucial to ask why is research still invisible in further education? Or, more specifically, why are intelligent, articulate and reflective colleagues in FE not contributing to the ever growing canon of educational research? There is still no academic journal dedicated to research in and on further education. Of articles published in the last 10 years by the journal sponsored by the Further Education Research Association, Research in Post-Compulsory Education, under a quarter (23\%) are written by FE practitioners (57 articles out of a total of 248). Yet it is clear that many colleagues in FE do carry out research and advanced scholarship, overwhelmingly in their own time. The PG Cert FE/Cert Ed FE contained modules on research and a research report as mandatory (now removed) which demonstrated that 
many FE tutors could and did produce valuable research. We asked colleagues in FE to reflect on doing research in their sector and those who are named managed to find time in their busy schedules to offer some reflections, for which we are grateful.

Elliott (1996) explored a number of very practical barriers to doing research that colleagues within FE face, some of which we shall also explore within this article, but through a contemporary lens. The discourse of education has changed over recent years, and this is an important new dimension that has greatly influenced our thinking on the position and status of research in the colleges and universities that we are familiar with. The lexicon that we possess, or that we currently utilise, will impact upon the decisions that we make. What words are we using in order to make decisions about the purpose and practice of education? How are we describing ourselves as educators? Pring (2007, p.326) asks us to consider the language through which 'educational and training provision is described and evaluated'. We may not be aware of the impact that the dominant discourse has upon our thinking, but Pring (2007, p.328) suggests that 'it is language which shapes our consciousness' and which has led educationalists into uncritical acceptance of the 'trite', influenced by the 'impoverished metaphors which govern our language and thought'. Language is our means of thinking, of making decisions.

So just how do the reflections of FE colleagues compare to the problems posed by Elliott 17 years ago? Elliott (1996, p.104) argued that for there to be a research culture college managers 'would need to develop an institution-wide research policy and ensure that its organisational and management structures supported its implementation'. This would then be reflected in the processes of establishing research roles and incorporating research activity into institute statements and plans. So why does this not happen? Elliott suggested a number of reasons for this in 1996: that compared to the HE sector fewer staff hold research degrees, staff development and training is underfunded, contracts are filled with teaching and administration and are inflexible. We found current evidence of research and scholarly activity being squeezed in FE, as colleagues reflect on a number of issues:

Planning for and marking HE work isn't seen as any different to any other planning and marking for any other course and there is no appreciation of difference between research for lesson planning and research for writing...There is no mention of academic writing in staff development in college and there is no help available... Research and writing for publication do not appear to be an important aspect of FE colleges at all. To my knowledge there is no writing for publication going on in any 
department in my own setting. I am only aware of research going on as part of individuals' MA study... (Tutor A)

I was invited to write with a number of people who have gone on to publish widely and very successfully. However, by that time I had begun lecturing at an FE College. My new job consumed all of my time and energy and indeed it continues to do so...I was told that all staff have time on their timetables to research - that'll be the 10 minutes between lessons when you have to fit in a toilet stop and your lunch break then! (Tutor B)

...time allocation could be given for increasing qualifications but not for pure research...the research I needed to complete to gain additional qualifications was seen to be secondary to the actual qualification, it was a means to an end. No time allocation requests were ever given for 'stand-alone' research that did not result in actual qualifications. (Tutor $\mathrm{C}$ )

...although [managers in FE] ...may appreciate the particular need of higher level teaching staff to extend their own learning in line with colleagues in the HE sector, they have not made provision for the pursuit of 'scholarly activities'... (Tutor D)

There persists the view that a college tutor gaining a qualification which results in a box ticked will, somehow, add to value. References to the marginal nature of research within FE were laced throughout colleague's responses. It appears that, still, 'Research is not regarded as a core activity for lecturers in FE' (Elliott, 1996, p.106). As Elliott goes on to discuss, colleges are yet another victim of this country's 'quick fix' approach to education. Student numbers and performance indicators are what count, and research does not comfortably align with these necessities. Pring (2007, p.319) laments how 'Politicians are in a hurry for results, and are understandably impatient of those who answer questions with yet more questions'. Such an approach seems to us to have infused the whole education system such that 'deep research', which attempts to create more questions, is secondary to answers that will improve results. We discuss this shift in the purpose of research later.

Within our sample of FE tutors, Elliott's words still ring true that 'Tired staff may find that research becomes a daunting prospect' (Elliott, 1996, p.105) but that tiredness seems to 
be a permanent feature of all teaching currently, whether based within the further or higher education arena. Added to the pressure of teaching hours is the requirement to mark hundreds of scripts in a limited number of working days (always creeping into evenings and weekends), annual evaluation reports, reviews, action plans, revalidations, the writing of new modules. All teaching staff, whether HE or FE, experience these pressures. What is more significant is why HE staff feel an obligation beyond, an intrinsic motivation to research, whereas FE staff do not appear to. Elliott (1996, p.106) claimed that research was prioritised above teaching in $\mathrm{HE}$, but we now wish to question this assumption. It is, we believe, a consequence of the intensification of HE work, particularly during the continued expansion of the sector over the last period, that HE priorities have become more functional than they were. Student Experience Surveys and Key Information Sets now decide whether our university courses are 'value for money'. The notion that a university might be valued upon the rigour of the research taking place seems rather antiquated and irrelevant within our current climate.

There is neither time nor space within post-compulsory education to explore philosophical issues for their own sake. Research is not recognised as relating to quality purely of itself, unless it is related to quality systems, quality of teaching, quality of student experience. We are now service-led. Ball (2006, p.11), comments that, 'Ethical reflection is rendered obsolete in the process for goal attainment, performance improvement and budget maximisations'. He wryly adds that 'Value replaces values, except where it can be shown that values add value' (Ball, 2006, p.11). Pring (2007, p.318) also bemoans this approach when he discusses how "there is deep suspicion of theory of any kind unless its relevance to improvement is clear and unmistaken" underlining the need for measurable results, or, as Pring (2007, p.318) describes it, 'obvious practical pay-off'. Odden and Kelley (1997; see Pring, 2007) were key players in aligning education more with the parameters of business and in creating a new language of education which discussed 'productivity targets', or as Harris and Ranson (2005, p.573) refer to it, 'the twin pillars of accountability (inspection, test scores, league tables) and standards (target setting, monitoring, raising achievement plans)'. Although Elliott (1996) described an FE system wherein virtually all research was fuelled by the evaluation of systems, the language of education has mutated still further since then, 'gradually enlisting the language of the business world... performance indicators...efficiency gains and investment' (Pring, 2007, p.325). And this change in language presages a change in our values and our thinking about education. 
Research in HE has now become just one other product on the production line, albeit one with a higher value than within the FE environment. And there is increasingly encouragement (through funding streams) to work on research that will improve the outputs of the university: student engagement, student achievement, student satisfaction. Increasingly universities, like colleges, are moving towards the "means/end' model of educational improvement' (Pring, 2007, p.323). Research is being used to justify and approve processes. But Healey et al. (2010, p.241) add another facet to this argument, that in the FE/HE emphasis upon 'value added' 'student perceptions of staff research as cutting edge and industry-linked may become increasingly significant'. As fees make degrees more career-based, and student expectations are raised, the 'pound of flesh' mentality will impact upon tutors more than ever. Students will expect their tutors to be both learned and current.

The Foundation Degree in Early Years places a very strong emphasis on the students' need to reflect, and there is positive encouragement of the students to become the type of reflective practitioners advocated by Schon (1983). However, a serious dilemma is being created by the pressures on tutors' time and the demands of course teaching. How will the students be able effectively to discern the difference between 'a piece of disguised nonsense' and 'something that is patent nonsense' (Wittgenstein, 1958, p.1.464) if their teachers are not given space to muse? The depth of thoughtful reflection needed for study within $\mathrm{HE}$, whilst being squeezed out by marketisation in universities, has never really been recognised within colleges. Yet it has been shown that a 'research-based approach to the curriculum', where students actively research for themselves, is highly effective (Healey et al., 2010, p.243). Many college tutors do not feel confident with a researchbased approach to teaching, as they, themselves, are not confident researchers. However, FE tutors clearly recognise and mourn the absence of space and time for research and reflection; and they clearly feel that this impacts upon the quality of experience being offered to their students:

I questioned the position of FE institutions in being able to deliver an experience of $\mathrm{HE}$ to students where parity of experiences would be so different within a university. The devaluing of research skills over a period of time, I felt ensured negativity and a lack of self-recognition and value. (Tutor $\mathrm{C}$ ) 
It seemed that it [FdA Early Years] was a progression route from level 3 and that it was something that just 'happened'- an extension of what occurred at level 3 and that anyone teaching HE in FE supported students to be able to 'do it'. (Tutor C)

Within our sample most of the college tutors felt that research, in the eyes of their managers at least, played no part in their FE careers and that it was certainly not on their teaching agenda. This was despite the obvious gains to be derived from it, one of which was a greater ability to empathise with the students that they were teaching.

...my research journey not only furnished me with essential skills and knowledge, but also brought me closer to my students because, whilst recognising that we all have very different stories, I knew what it was like to juggle work and family and study...There was certainly no encouragement to take the research further or to even know the details of my research findings, which were especially pertinent to the delivery of Higher Education within Further Education colleges. (Tutor D)

There exists an unhelpful disjuncture between research that generates knowledge that can inform teaching and research as a means of personal development. There remains a cultural 'jar' in the definition of teachers as technician/demonstrators or as reflective academics, whereby the concept of research is something separate from (and not integral to) teaching. A chasm persists between teaching and research, unless research is happening in order to justify 'teaching approaches'. As tutors we need to model the production of new knowledge. Teaching and research should be entwined, just as we support students on their learning journeys it is important to recognise and celebrate the fact that we are also on our own. The extent to which research is integral to teaching will not be recognised until managers within HE truly embrace the concepts of lifelong learning as opposed to productivity. It must be recognised that tutors are developing alongside their students, and that the tutor's own learning is not solely for the purpose of knowledge transmission to students, but for their own development as academics. Comments made suggested that the desire to learn, develop and challenge ourselves is integral to our role as evolving academics:

...I felt that the research journey had had a profound effect on both my personal and professional development, not only from the increase in confidence that accompanies achievement, but from the opportunities to develop knowledge and 
understanding, to have my ideas challenged and to have my understanding challenged... (Tutor D)

The Reggio Emilia approach to learning and development sees research as 'the stance, the attitude with which teachers approach the sense and meaning of life' (Rinaldi, 2005, p.148), it is vital for personal development. Giudici et al. (2001, p.150) also discuss the importance of documenting that search, that it is through language that the 'emotionally moving sense of the search for the meaning of life' obtains 'holistic fullness'. Research needs to be recorded; tutors need to write.

Because FE does not have its own research model, it follows on from, but also competes with, HE research in terms of publication. Just as FE research was hugely underrepresented when Elliott searched in 1996, it remains the case today. And even when HE does engage with research in FE, then it tends to be 'research on' rather than supporting research by or with FE institutions. There remains the issue that the language of this text talks about 'us and them', despite us working in close partnership. But the fact is that universities and colleges do have different cultures. And that has nothing to do with the qualifications or experience of those working there. It is the culture that they are working within which shapes the discourse. Let us be frank. The discourse of university is not one of 'expanding horizons through creative research'. It, just like FE colleges, prioritises numbers, profits, results. The key difference is that there is also recognition of the value of research outputs. It may be that this 'recognition' equates to REF scores, and there is still the view that 'real' research has to be empirical research, that this is 'worth' more. Writing and research which is simply thinking through ideas, or reflecting on literature is a less worthwhile enterprise in the 'rating' process, but it is reluctantly endured and even supported. The difference between the vast majority of FE and HE institutes is the expectation that in HE research, of some form, will be produced.

The growing trend towards partnerships between FE and HE institutions has proved to be an important feature in promoting a research culture (Elliott, 1996, p.109). Although the many hurdles faced by FE tutors makes the pursuit of research projects seem almost impossible, the desire of colleagues in FE to engage with the research process is clear, as is the support that they feel from their HE partner/s. In fact, the comments made by FE colleagues below make the research partnership between college and university seem less of a luxury and more of a necessity. 
I feel that in order to build more of a relationship with the university, I do need to be given time to write/research as I feel that we will not be able to develop any further in the HE partnership without doing so...I do not feel confident as a researcher/writer, but I tend to lack confidence in my own ability in general... However, working closely with the university team is really helping me personally to understand that I am more capable than I realise... my support network in this area is through my links with university. I have personally never written collaboratively, but I see it as a good way to begin writing for the first time. (Tutor A)

There has been, for some time, a clear pattern within the college that those in managerial positions, are encouraged to undertake Masters' programmes, and I believe that now, within my institution, there is, at last, a growing recognition that those of us who deliver higher education need to undertake relevant CPD and higher courses of study. However, the question remains, will staff pursuing Higher Degrees be given time for this study, and will those of us who are encouraged to undertake study and scholarly activity be given more than a few days a year in which to undertake a task which, currently, does not appear to merit any 'reward'... In the meantime, the promise of working collaboratively with our UW partnership team is providing the inspiration needed to write again! (Tutor D)

I am at the beginning of my research career...the freedom that this environment [the university] and my colleagues who I work with have been the critical catalyst. Even though I question my ability to research, I feel that this is residue from the FE environment...It is for this reason that I feel it is critical to develop the relationship with FE partners in order to ensure that either collaborative, or self-directed research is given the opportunity to be developed and sustained. (Tutor $\mathrm{C}$ )

It seems somewhat ironic that colleagues joining university from other backgrounds (in the case below an early years setting) felt more freedom and encouragement to research than those from an FE College. In this particular case the colleague felt 'supported by an imaginative and inspiring Local Authority mentor, interested parents, and the experience of undertaking the EYPS qualification' (Tutor E). Although direct support from the Local Authority in terms of time out of the setting only amounted to a few days, she says: 
I felt happy to give up time to work on this project as it was extremely satisfying to investigate the setting and our practice, and it started many interesting conversations with staff, and one or two of the parents. It was also an opportunity to develop the work of the nursery in a way that would not have been possible otherwise, and this helped me to feel that the roof had been raised and the walls pushed back - so to speak! - so that we could make new discoveries within a larger intellectual space. (Tutor E)

Is the issue that tutors in FE (just like many tutors in $\mathrm{HE}$ ) need to start to see research differently? Do we need to focus more upon opening up intellectual 'space', continuing our own learning journeys, and less upon producing measurable results? Just as we as tutors need to re-imagine the way that we approach research with student-practitioners (Solvason, 2012), so it may be helpful for college tutors to re-think the purpose of their own research. Much of this has to do with confidence and empowerment. There is an element of risk of opening oneself to criticism that exists when research is put into the public sphere. Many feel that to avoid this one has to follow the 'rules', or as one college tutor described the process, 'research by sat-nav'. Those who are less confident seek the reassurance that they are doing it 'right'. McNiff's (2011) likening research to 'stepping off a cliff, who knows what might happen' can be debilitating rather than enabling. Exploratory, reflexive research represents a loss of power and opens oneself up to question, which is a position some teachers may find both unfamiliar and uncomfortable.

Just as our students need to claim research for their own development, so do we, as teachers and as academics. One college tutor referred to research as a 'wonderfully empowering and somewhat indulgent activity'. It is such a shame that many tutors do not feel empowered at all, but rather intimidated by research. Perhaps it would be different if tutors felt reassured that research is not about rigidly abiding by strict methodological parameters, but about 'enabl[ing] new, valid understandings to develop; understandings that empower practitioners to improve their work for the beneficiaries in their care' (Dadds and Hart, 2001, p.169). It is important that we are not lulled into seeing research as a detached collation of information and analysis, but as a method of exploring our own ideologies, our own practice. It is important that research does not become another means of ticking a quality improvement box, but that it is used to inform understanding, and, as a direct or indirect result to improve practice. Dadds and Hart (2001, p.169) stress that 'Professional intention should be informing research processes, not pre-set ideas about 
methods of techniques'. Research can be the means by which we develop both personally and professionally and as such should be dictated by us, it is not a process by which we learn to conform to a set of systems and mechanisms.

It would appear that college tutors, and particularly those involved with the delivery of HE level courses, need to start to be a little more selfish and demand time for their own professional improvement. Shamai and Kfir (2002, p.398) discuss how involvement in the analytical processes of research and the production of findings for peer review will 'clearly help to sustain college teachers on the appropriate academic level'. Where did the recognition of the intrinsically entwined nature of teaching and research become lost? How did those two things become so clearly separated upon our academic production line? When discussing some of the barriers to research activity Shamai and Kfir (2002) refer to the loss of a long term vision of development for institutions. This appears to be the case in the UK, where we are so bound up with 'day-to-day, short-term struggles for existence' (Shamai and Kfir, 2002, p.401), that we have lost the image of our institutions as seats of academic exploration.

If, as Remmik et al. (2011, p.189) claim 'Professional identity is an ongoing process of interpretation and re-interpretation of experiences', how will, what essentially seem to be viewed as incomplete or stifled experiences, impact upon academics who are denied the time or the space to be 'academic'? That sense of suffocation is clear in the following comments:

My new job consumed all of my time and energy and indeed it continues to do so...I feel that much of my energy and enthusiasm for research and writing has ebbed away. I'm not in a place where this is even on the agenda. Maybe I need to change my place? (Tutor B)

Teachers work on average 750 teaching hours per year and there are other duties, such as covering lessons, admin duties, meetings, compulsory weekly training, marking, exam invigilation, interviews and enrolment duties, etc. (Tutor A)

The many pressures placed upon tutors' time results in the transmission method of teaching and learning being prioritised most often at FE level. FE retains an 'expediency' culture of learning where there is little time or leisure to develop Biggs' (2003) 'deep' 
approach to learning. Viewed in this way the necessity for tutors to research in order to deepen their own understanding is obvious. What is also obvious is college tutors' desire to engage in lifelong learning. This is not an external pressure, it is an innate need.

So how do we move on? How do we, as collaborating colleagues, embed research within our own personal practice, despite the diverse research cultures from which we originate? It may be that we carry on precisely as we have begun. Shamai and Kfir (2002) describe models of research activity. In their case this supposes its establishment within one college, but there is no reason why their 'Collaborative Centralised' model cannot be extended across partnerships. 'This model is based on a core of skilled personnel' (Shamai and Kfir, 2002, p.404), with the aim that wider colleagues are drawn in. In this way, fledgling researchers are supported and empowered, and the greater the number of researchers that become involved, the more noteworthy the research culture becomes. Hopefully this is just the beginning of our research community. Perhaps as we all grow and develop in confidence this may expand into a multi-core model, but to start with one research active group will suffice.

But what about a tutor's own identity formation? If tutors in FE are continually being stifled in what they see as an important area of their development, how will this affect their professional identity? If, as Remmik et al. (2011, p.189) suggest, 'professional identity can be viewed as a form of argument the individual uses to justify, explain, and provide meaning to their activity, situations and values', then how does it affect them when that argument is unbalanced? What happens when the real and the desired self are vastly different with little chance of that being reconciled? What often happens in reality is a dissatisfaction, where academics are driven to work ridiculous hours which eat in to their personal and family time to enable their own academic and professional development. One tutor said:

I carry out research in my own time to try and ensure subject currency. This is motivated by my own values and beliefs about being 'a professional' rather than any messages I am given by the college. (Tutor B)

What is clear is that the desire for college tutors to research and deepen their own understanding is neither simply a superficial means to an end, or a response to an external pressure, it is an innate need. Their desire to engage in lifelong learning is patent: 
Now, a year on, the opportunity to be part of the university has, I feel, given me back my sense of self back, in belonging to a research community.... It is for this reason that I feel it is critical to develop the relationship with FE Partners in order to ensure that either collaborative, or self-directed research is given the opportunity to be developed and sustained. Looking back I feel that the research journey has been an emotional one and reflecting upon this I hope this emotion is clear. The frustrated researcher has grown wings! (Tutor C)

The need for tutors to engage with research is a need that conflicts with the 'quick fix' approach prevalent throughout FE/HE.

'Scholarly activity' is not seen as necessary in order to do the job role in FE. (Tutor A)

It is both difficult and inappropriate for us to prescribe a quick fix solution to the problem of the marginalisation of research in FE - indeed, we positively reject such a prescription. However, our experience of working with the colleagues whose views are represented in this article leads us to offer an organic solution that, crucially, does not depend upon formal institutional structures, management arrangements, extrinsic reward or external funding. With our partners we are building a participant research community along the lines of the collaborative centralised model described earlier. We are finding that this community is purposeful, creative, democratic, supportive, productive, and sustainable. Most importantly, as the need for evidence-based practice and the trend for governmental organisations, communities and individuals to use research to bring about change become more prevalent (Elliott et al., 2010, p.293), we believe that our community of research practice has the potential to make an impact upon the character and organisation of educational research in our institution and beyond. It embraces perspectives from across post-compulsory education and more widely. It is a network to support practitioner research and, we would suggest, has the potential to enhance practice by up-skilling and giving confidence to tutors and their students alike.

The model has, importantly, also informed our own teaching, such that we now fully recognise the serious barriers to understanding research faced by our students, who often start with the feeling that research is outside of their domain rather than something innate and personal to them. We feel that if, truly, 'education should begin and end in research' 
(Whitehead, 1962, p.58), then our research community can offer the means to progress towards Whitehead's laudable goal of 'the production of creative wisdom' (Whitehead, 1962, p.58), and an antidote to the more impoverished notions of education that we have described above.

\section{Acknowledgement}

The authors gratefully acknowledge the insightful comments on a draft version of this article made by the tutors cited in the study: Frances Brett, Jodie Davies, Angela Hodgkins, Carole Pannell and Michelle Rogers. We have their permission to cite their names and, where appropriate, we have incorporated their suggestions into the final text.

\section{References}

Ball, S. (2006) Education policy and social class: the selected works of Stephen J. Ball. London: Routledge.

Biggs, J. (2003) Teaching for quality learning at university. Buckingham: The Society for Research into Higher Education and Open University Press.

Cantor, L. and Roberts, I. (1972/1986) Further education in England and Wales. $3^{\text {rd }}$ edn. London: Routledge and Kegan Paul.

Carr, W. and Kemmis, S. (1986) Becoming critical. Lewes, East Sussex: Falmer Press.

Dadds, M. and Hart, S. (2001) Doing practitioner research differently. London: Routledge Falmer.

Elliott, G. (1996) 'Why is research invisible in further education?', British Educational Research Journal, 22(1), pp. 101-111.

Elliott, G., Fourali, C. and Issler, S. (2010) Education and social change: connecting local and global perspectives. London: Continuum. 
Giudici, C., Rinaldi, C. and Krechevsky, M. (eds.) (2001) Making learning visible: children as individual and group learners. Italy: Reggio Children, Reggio Emilia.

Harris, A. and Ranson, S. (2005) 'The contradictions of education policy: disadvantage and achievement', British Educational Research Journal, 31(5), pp. 571-587.

Healey, M., Jordan, F., Pell, B. and Short, C. (2010) 'The research-teaching nexus: a case study of students' awareness, experiences and perceptions of research', Innovations in Education and Teaching International, 47(2), pp. 235-246.

Higher Education Funding Council for England (2012) Student number controls for 201314. News briefing, Bristol, HEFCE. Available at: http://www.hefce.ac.uk/news/newsarchive/2012/name,72760,en.html (Accessed: 10 May 2012).

McNiff, J. (2011) 'Exploring practice based research', BECERA Annual Conference. Birmingham 23-24 February.

Odden, A. and Kelley, C. (1997) Paying teachers for what they know and do: New and smarter compensation strategies to improve schools. Thousand Oaks, CA: Corwin Press.

Pring, R. (2007) 'Reclaiming philosophy for educational research', Educational Review, 59(3), pp. 315-330.

Remmik, M., Karm, M., Haamer, A. and Lepp, L. (2011) 'Early-career academics' learning in academic communities', International Journal for Academic Development, 16(3), pp. 187-199.

Rinaldi, C. (2005) In dialogue with Reggio Emilia. London, RoutledgeFalmer.

Schon, D. (1983) The reflective practitioner - how professionals think in action. New York: Basic Books. 
Shamai, S. and Kfir, D. (2002) 'Research activity and research culture in academic teachers' colleges in Israel', Teaching in Higher Education, 7(4), pp. 397-410.

Solvason, C. (2012) 'Research and the early years practitioner-researcher', Early Years: An International Journal of Research and Development, 33(1), pp. 90-97. Available at: http://dx.doi.org/10.1080/09575146.2012.665360 (Accessed: 23 May 2012).

Whitehead, A. (1962) The aims of education and other essays. $2^{\text {nd }}$ edn. London: Ernest Benn.

Wittgenstein, L. (1958) Philosophical investigations. $2^{\text {nd }}$ edn. London: Basil Blackwell.

\section{Author details}

In Carla's current role as senior lecturer at the University of Worcester her key area of responsibility is around the area of research. This involves ensuring that student practitioners are given the support that they need to carry out worthwhile research projects, but also encouraging colleagues to reach their full research potential. Her most recent publications and presentations have explored the topic of ethicality and how we can embed this within professional development. With her colleague, Rosie Walker, she has co-authored a book to support Early Years practitioners in their research projects, which is due to be published in the summer. She is currently involved in a longitudinal research project (that will span over three years) which explores ways of supporting children's speech and language development within a primary school.

The majority of Carla's working life was spent as a primary school teacher. During that time she completed a Masters in Gender, Literature and Modernity (classic literature remains a passion of hers) and a $\mathrm{PhD}$ in Education, specifically looking at concepts of inclusion. Before starting work at Worcester, in 2009, she spent a year as a consultant for the children's communication charity, I Can.

Geoffrey is Professor of Lifelong Learning and Director of Strategic Partnerships at the University of Worcester. He has worked in school, further and adult education, and 
has previously held posts with the University of East London and the Open University. Geoffrey chairs the Research Degrees Board at the University of Worcester, and is himself an active researcher specialising in lifelong learning and educational leadership. He is Chair of the Further Education Research Association, and Editor in Chief of the international peer refereed journal Research in PostCompulsory Education since its launch in 1995. Geoffrey is an accredited mediator and currently serves as a Board member of the Office of the Independent Adjudicator. His most recent book is an edited collection in collaboration with $\mathrm{Dr}$ Chahid Fourali and Dr Sally Issler, Education and Social Change: Connecting local and global perspectives, published by Continuum Press. 